Trinity University

Digital Commons @ Trinity

Psychology Faculty Research

Psychology Department

1994

\title{
Depressive Deficits in Recognition: Dissociation of Recollection and Familiarity
}

Paula T. Hertel

Trinity University, phertel@trinity.edu

S. Milan

Follow this and additional works at: https://digitalcommons.trinity.edu/psych_faculty

Part of the Psychology Commons

Publication Details

Journal of Abnormal Psychology

\section{Repository Citation}

Hertel, P.T., \& Milan, S. (1994). Depressive deficits in recognition: Dissociation of recollection and familiarity. Journal of Abnormal Psychology, 103(4), 736-742. doi: 10.1037/0021-843X.103.4.736

This Article is brought to you for free and open access by the Psychology Department at Digital Commons @ Trinity. It has been accepted for inclusion in Psychology Faculty Research by an authorized administrator of Digital Commons@ Trinity. For more information, please contact jcostanz@trinity.edu. 


\title{
Depressive Deficits in Recognition: Dissociation of Recollection and Familiarity
}

\author{
Paula T. Hertel and Stephanie Milan
}

\begin{abstract}
Dysphoric and nondysphoric students (48 women and 24 men) participated in an experiment that was designed to separate automatic and controlled uses of memory in a modified recognition paradigm. First, they judged the relation of target words to paired words. Later they made recognition decisions on target items alone or in the context of the original paired item. The use of L. L. Jacoby's (1991) process dissociation procedure revealed depressive deficits in estimates of recollection but not in estimates of familiarity. The paired test improved recollection for all subjects and showed a trend in the direction of increased familiarity. These outcomes support approaches to depressive cognition that emphasize impaired cognitive control.
\end{abstract}

Depressed mood is associated with deficient performance in some tests of memory. Direct tests of free recall show the association most frequently (see reviews by Hartlage, Alloy, Vazquez, \& Dykman, 1993; Williams, Watts, MacLeod, \& Mathews, 1988). Indirect tests of unaware remembering have not yet shown it (see Roediger \& McDermott, 1992). In the middle, tests of recognition give mixed results. Watts, Morris, and MacLeod (1987) saw this mixture as a reflection of variations in the sensitivity of recognition measures, and indeed there are now several studies that have used signal-detection analyses to reveal evidence of depression-related deficits in recognition accuracy (e.g., Channon, Baker, \& Robertson, 1993; Hertel \& Hardin, 1990; Watts et al., 1987). Our purpose was to take a different tack in the investigation of depressive performance on tests of recognition. The approach rests on a theoretical analysis of recognition processes developed by Jacoby (1991). We describe this approach first and then relate the analysis to theoretical frameworks for studying depressed moods and memory.

Recognition decisions can be based either on recollection of an item's prior occurrence or on the more general sense that the item feels familiar (Jacoby \& Dallas, 1981; Mandler, 1980). Familiarity-based decisions need not involve attention to past events; in that sense, they reflect automatic influences of prior experience (see Hasher \& Zacks, 1979). Recollection (remembering that an item occurred in a specific context) refers to conscious reflection on the past. With this distinction in mind, Jacoby (1991) argued that performance on memory tests in general involves both automatic and controlled uses of past

Paula T. Hertel and Stephanie Milan, Department of Psychology, Trinity University.

A portion of this research was conducted by Stephanie Milan and reported in her senior thesis.

We are grateful to Christine Winston and Rome Salas for help in collecting data and to three anonymous reviewers for their very helpful comments.

Correspondence concerning this article should be addressed to Paula T. Hertel, Department of Psychology, Trinity University, 715 Stadium Drive, San Antonio, Texas 78212. Electronic mail may be sent to PHERTEL@TRINITY.EDU. experience; recognition decisions in particular are based on both feelings of familiarity and conscious recollection.

Jacoby and his colleagues (e.g., Jacoby, 1991; Jacoby, Toth, \& Yonelinas, 1993) have developed a process dissociation framework for understanding the relative contributions of automatic and controlled uses of memory in recognition and other tests. Essentially, the approach is to place those two types of procedures in opposition to each other, through the use of different test instructions. On an inclusion test for recognition, subjects are instructed to endorse as old all items from two prior phases of the experiment. Subjects respond on the basis of familiarity or on the basis of recollecting a prior occurrence; familiarity and recollection act together and in the same direction to facilitate recognition of prior items. On the exclusion test, however, subjects are instructed to exclude items from the first (or critical) phase of the experiment, to call only items from Phase 2 old. In this case, familiarity and recollection operate in opposition for Phase 1 items; subjects respond old only to the extent that they are guided by familiarity, because if they recollect the item's occurrence in Phase 1, they will correctly respond new.

Jacoby's (1991) framework makes certain assumptions about the probability of responding old to an item from Phase 1 under each instruction. In inclusion, the probability of responding old $\left(O_{\mathrm{i}}\right)$ equals the probability that the item is recollected from Phase $1(R)$ or, if it is not recollected, the probability that it feels familiar $([1-R] F)$. In exclusion, the probability of responding old $\left(O_{\mathrm{e}}\right)$ simply equals the probability that the item is familiar but not recollected from Phase $1([1-R] F)$. Therefore, the probability that an item is recollected from Phase 1 can be calculated algebraically:

$$
\begin{aligned}
O_{\mathrm{i}} & =R+(1-R) F \\
O_{\mathrm{e}} & =(1-R) F \\
R & =O_{\mathrm{i}}-O_{\mathrm{e}}
\end{aligned}
$$

Estimates of recollection are thus obtained by subtracting the proportion of items judged old on the exclusion test from the proportion judged old on the inclusion test. Estimates of familiarity are then derived by substitution.

The procedure is called process dissociation because a variety 
of independent variables have produced functional dissociations in the estimates for recollection and familiarity (or similar parameters in tests of stem completion). Relevant to our concern, several manipulations have affected estimates of the component for recollection but left estimates of the automatic component invariant. These include semantic versus nonsemantic orienting tasks (Toth, Reingold, \& Jacoby, 1994), degree of attention (Jacoby et al., 1993), and list length (Yonelinas \& Jacoby, in press). In regard to recognition memory in particular, Jacoby (1991) showed that dividing subjects' attention at the time of the test reduces the size of the estimate for recollection (disrupts it) but leaves the automatic effects of prior experience intact (does not affect familiarity). Similarly, we intended to test whether depressed or dysphoric states operate like divided attention at either study or test phases in reducing the recollective aspect of recognition memory.

In the literature on depressive memory, several investigators have argued that depressive impairments reflect reduced cognitive capacity (see Hasher \& Zacks, 1979; Williams et al., 1988). Resource allocation theory, for example, asserts that depressed subjects' cognitive resources, perhaps because they are pervasively consumed by self-relevant thoughts, are insufficient to produce good performance on more resource-demanding tasks (Ellis \& Ashbrook, 1988). With a different emphasis, we understand such impairments as reflections of deficits in cognitive initiative (Hertel \& Hardin, 1990; Hertel \& Rude, 1991). The notion is that depressed people experience difficulties in monitoring and self-sustained attention but that they are quite capable of performing resource-demanding tasks when guided to use procedures that nondepressed subjects perform on their own initiative. For example, it has been shown that depressed and dysphoric persons can benefit from procedures designed to hold their attention on the task (Hertel \& Rude, 1991) and to monitor the relevance of the past (Hertel \& Hardin, 1990). Both the cognitive-effort and the initiative perspectives on depressive memory emphasize cognitive control as the locus of depressive impairments. From both points of view, then, one may expect deficits in estimates of recollection but not in estimates of familiarity as a basis of recognition memory.

In addition to testing that prediction, a further goal of our study was to determine which component of recognition was affected by the reinstatement of prior context. Contextual cues provided at the time of the test may increase the familiarity of the target items. They may also improve recollection if they establish a basis for distinguishing among items from the two lists. In Phase 1 of this experiment, the subjects rated target words for their degree of relation to paired words; in Phase 2, they tried to learn another set of words presented singly. Then on the test, Phase 1 targets were presented with the original paired words, but Phase 2 words and distractors were presented with new paired words. This paired test was administered to half of the subjects, whereas the others saw single targets, Phase 2 words, and distractors. In short, the paired test provided context that either made the target seem more or less familiar or established a basis for list discrimination to aid recollection. The process dissociation procedure ought to reveal the nature of these contextual effects, as well as determine whether it depends on the subject's emotional state. In searching for ways to repair depressive deficits in cognitive control, we hoped that the paired test would increase the recollective component of recognition for dysphoric subjects.

In summary, because depressive deficits are typically attributed to impaired cognitive control, we predicted a dissociation in the component processes of recognition as a function of subjects' emotional state. Dysphoric subjects were expected to show deficient recollective processes but unimpaired automatic influences. Second, we sought to discover whether the deficit in recollection would be partially repaired by the provision of context from the rating phase at the time of the test.

\section{Method}

\section{Overview}

The experiment was run in three phases. In Phase 1, all subjects rated the semantic relatedness within 60 pairs of unrelated words. The first members of the pairs served as target items on the later recognition test; the second members provided context for the relatedness judgment. In Phase 2, subjects listened to a tape of 60 additional words under expectations of a memory test. The sole purpose of Phase 2, however, was to provide a set of words for the recognition test that would consistently require a judgment of old. Without this phase subjects would be asked to call all items new under the exclusion instructions.

In the final phase the recognition test was given. Words were ordered in blocks according to instructions to include items from Phase 1 or to exclude them. Half of the subjects in each mood condition took a singleitem test; the others made recognition judgments about the first members of pairs, wherein the second members recapitulated the original context of Phase 1 words. The second members for pairs of Phase 2 and new words, of course, were new to the subjects. Subjects were told to decide about the first word in the pair and were advised that the second item in the pair might help them to decide.

\section{Subjects}

A total of 89 students initially participated in the experiment; the final sample of 72 was selected according to the following procedures.

Procedures for selection. First, we administered the Beck Depression Inventory (BDI; Beck, Ward, Mendelson, Mock, \& Erbaugh, 1961) to a lower division psychology class approximately 2 weeks before individual experimental sessions were scheduled; additional classes were surveyed when needed throughout the period of the experiment. The students did not sign the inventories but did provide a signed consent form that was separated from the inventory after both forms were coded with a subject number. After the inventories were scored, the subject numbers of students selected for recruiting were assigned to conditions of the experimental design in a manner that ensured counterbalancing within each experimental and mood condition. Then the experimenter, unaware of mood information, matched the subject number and condition assignment with the student's name and called the student to request participation. (Ten students declined the invitation.)

Students who scored over 9 (but generally higher) were recruited for the dysphoric sample; students who scored from 1 to 7 were recruited for the nondysphoric sample. Students received credit toward their course grade for filling out the inventories and, separately, for participating in the experiment.

At the end of the experimental session, the subjects filled out the BDI, the State-Trait Anxiety Inventory (STAI; Spielberger, Gorsuch, Lushene, Vagg, \& Jacobs, 1983), and a mood and health questionnaire, sealed them in envelopes coded with subject numbers, and returned the envelopes. The subjects were led to believe that the packet of inventories was not related to the topic of the experiment. Items on the question- 
Table 1

Mean Scores on the Mood Indexes

\begin{tabular}{|c|c|c|c|c|}
\hline \multirow[b]{2}{*}{ Index } & \multicolumn{2}{|c|}{ Dysphoric } & \multicolumn{2}{|c|}{ Nondysphoric } \\
\hline & $\begin{array}{l}\text { Single } \\
\text { item }\end{array}$ & Paired & $\begin{array}{l}\text { Single } \\
\text { item }\end{array}$ & Paired \\
\hline $\begin{array}{l}\text { Beck Depression Inventory } \\
\text { State-Trait Anxiety Inventory }\end{array}$ & 17.7 & 17.1 & 4.9 & 3.2 \\
\hline State & 48.8 & 53.3 & 40.5 & 36.1 \\
\hline Trait & 51.4 & 53.2 & 35.7 & 39.3 \\
\hline
\end{tabular}

Note. Scores are reported by mood (dysphoric vs. nondysphoric) and test condition (single item vs. paired). $n=18$ for all Beck Depression Inventory and State-Trait Anxiety Inventory, State scale administrations; for State-Trait Anxiety Inventory, Trait scale, $n s=17,17,15$, and 17 , respectively.

naire allowed us to verify the dysphoric and nondysphoric states of the subjects. We set aside the data from 8 subjects whose BDI scores did not remain in the initial category or whose responses on the questionnaire clearly ruled out a dysphoric state (see Deardorff \& Funabiki, 1985).

Final sample. The data from an additional 9 subjects ( 5 nondysphoric and 4 dysphoric) were set aside because they clearly misunderstood the instructions about inclusion and exclusion. Twelve women and 6 men were assigned to each of the conditions that resulted from the combination of mood (dysphoric vs. nondysphoric) and type of test (single-item vs. paired). Also, in each condition, 3 subjects were assigned to each of the six word-presentation conditions, which we describe later; one assignment error (for a dysphoric subject taking the single-item test) resulted in uneven sample sizes across the word-presentation conditions. The average number of days between the first and second administration of the BDI was 16.

Mean scores on the postexperimental BDI and the STAI are listed in Table 1 . These means reliably differed in terms of mood group but not for the type of test. Bivariate correlations among these measures ranged from .73 to .78 and were all reliable.

\section{Materials}

Target words. From Kuçera and Francis (1967), we selected 180 nouns and adjectives with frequencies below 70. All words contained five, six, or seven letters. One third were neutral, one third negative, and one third positive in emotional valence. ${ }^{1}$

The 180 words were placed in six groups, each of which contained equal numbers of words from each valence and part of speech. Word frequency and length were closely balanced. Next, two of the six groups were assigned to each of three experimental lists; one of the two groups on each list was later used on the inclusion test and the other, on the exclusion test. The purpose of the three main lists was, however, to provide 60 items each for Phase 1 (relatedness ratings), Phase 2 (heard items), and the test (new items). During the test each subject encountered all 180 words but in different roles (rated, heard, or new items) and under different instructions (inclusion or exclusion). These two factors produced the six counterbalanced, word-presentation conditions.

Lists for Phase I and Phase 2. The words on each of the three main lists were randomly ordered for presentation during Phase 1 or Phase 2, with the exceptions that no 2 words of the same valence or from the same original block appeared consecutively. For presentation during Phase 2, each list was tape recorded by a female experimenter at a rate of approximately $1.5 \mathrm{~s}$ per word.

To construct the rating task in Phase 1, each word was paired with an extralist word of the same length, part of speech, and frequency. Each paired word was emotionally neutral, semantically unrelated to the target word (according to the judgment of the authors and an experimenter), and followed it on the same line in the computer display.
Test list. The practice section of the test list consisted of 3 words (one of each valence) from each of the six original groups. These words were assigned to one of two practice blocks-one inclusion and one exclusion-of 9 words each. Responses to these 18 items were not analyzed.

The main part of the test list consisted of the remaining 27 words from each of the six original groups. They were redistributed across six test blocks of 27 words each. Each test block contained 9 Phase 1 words, 9 Phase 2 words, and 9 new words. Three test blocks were assigned to inclusion and three, to exclusion instructions, with the order alternated across blocks. Therefore, under each instruction the subjects saw 27 words they had rated, 27 they had heard, and 27 that were new.

Within each block of 27 , the words were grouped according to valence. The order of presentation within valence was random but limited to no consecutive occurrences from the same experimental list.

In the test phase the words occurred as single items for one half of the subjects and as the first members of pairs for the other half. In the paired condition the words were presented together with their partner from the Phase 1 rating task. For Phase 2 and new words, we used the partners that appeared when those words were Phase 1 words for other subjects.

\section{Procedure}

Phase 1. First, the subjects were instructed to judge the degree of semantic relatedness within each of 60 word pairs. They were told that many of the words in the pairs would not seem to be very related but that, nevertheless, they should make their judgments carefully. Each pair of words was presented for $2 \mathrm{~s}$ on the same line (target first) and centered on the screen; words appeared in white against a black background. With their offset, a scale from 1 (unrelated) to 5 (very related) appeared at the bottom of the screen for $2 \mathrm{~s}$. The subjects responded by pressing the number key that corresponded to their judgment. After a blank screen that lasted $500 \mathrm{~ms}$, the next pair of words appeared.

Phase 2. Next, the subjects were told to listen carefully to a list of recorded words in anticipation of a later memory test. They were told

\footnotetext{
'Emotional valence was originally included as a factor in the design, in an attempt to obtain evidence for mood-congruent recollection or familiarity No such evidence was found; instead, a series of main effects revealed that neqative words were endorsed most frequently (positive next and neural least) when they served as new items or heard items or were used in the exclusion test. Estimates of familiarity were highest for negative words; estimates of recollection were lowest. These differences may be attributed to the fact that negative words were most emotional and to the probability that they were interrelated to a greater degree than were words in the other categories and therefore least discriminable.
} 
that the list was long and that they would not be expected to remember all the words. They might, however, want to repeat the words to themselves or to do whatever normally facilitated their memory. The tape contained 60 words, read at a 1.5 -s rate.

Test. In the final phase the words on the test list were presented for $6 \mathrm{~s}$ each in the middle of the screen, either alone or as the first word in a pair, depending on the testing condition to which the subject had been assigned. Under both inclusion and exclusion conditions, the subjects responded by pressing keys labeled old and new. The $N$ and $\mathrm{V}$ keys on the keyboard were used for this purpose; the subjects rested their index fingers on those keys. A blank screen of 500-ms duration separated displays; responses that were made after the offset of the item were counted as missing.

Before each practice block and test block, the screen displayed the instruction for the upcoming set of items. These instructions read, "Include items from Phase 1 by typing OLD" and "Exclude items from Phase 1 by typing NEW." For half of the subjects, the first practice block was an inclusion block, and for the other half it was an exclusion block; blocks then were alternated between instructions, although the order of words remained constant. These first two instructional screens were used as opportunities to remind the subjects about the requested judgments. When ready to proceed, the subjects pressed a key to begin the block.

At the beginning of the single-item test phase, the subjects read the following instructions:

The next task is a recognition task. You will be asked to recognize words from the previous phases in one of two ways. First, when the instruction to INCLUDE is given, your task is to strike the OLD key if the item occurred previously in this experiment. You may remember that the item occurred as the first member of a pair on the computer screen, or you may remember the item from the audio tape. Strike NEW only if you do not remember the item from either phase. In other words, when you are told to INCLUDE, strike OLD if the item was previously presented and NEW if it was not. Second, when the instruction to EXCLUDE is given, you should exclude items from Phase 1 (the ones you judged on the computer). If the item feels familiar but you remember that it occurred in Phase 1, strike NEW. Also strike NEW if it is a new item. Strike OLD only if the item seems familiar but you do not remember it occurring in Phase 1 on the computer. By the way, the second members of the pairs in Phase 1 will not appear as items in these tasks. Please note that you will always strike OLD to items from the audio tape. However, you should not try to remember the tape; that's too hard. Just trust that if an item seems familiar but you do not remember it from Phase 1, it was probably on the tape.

These instructions were modified for subjects in the paired test condition. They were told:

The next task is a recognition task. Pairs of words will appear on the screen, one pair at a time. You will be asked to determine if the first word in the pair occurred in the previous phases. If the first word was in Phase 1, when you judged words on the computer, you can trust that the second word was also paired with it in Phase 1. But if the first word was not in Phase 1, the second word on the screen will be a new word. You will make decisions about the first words of the pairs in one of two ways, and you may find that the second words help you to make those decisions. First, when the instruction to INCLUDE is given, your task is to strike the OLD key if the item occurred previously in this experiment. You may remember that the item occurred as the first member of a pair on the computer screen, or you may remember the item from the audio tape. Strike NEW only if you do not remember the item from either phase. In other words, when you are told to INCLUDE, strike OLD if the item was previously presented and NEW if it was not. Second, when the instruction to EXCLUDE is given, you should exclude items from Phase 1 (the ones you judged on the computer). If the item feels familiar but you remember that it oc-
Table 2

Mean Estimates of Recollection and Familiarity

(and Standard Deviations)

\begin{tabular}{lcc}
\hline Measure and group & Single item & Paired \\
\hline Recollection & & \\
$\quad$ Nondysphoric & $.31(.19)$ & $.54(.20)$ \\
$\quad$ Dysphoric & $.20(.24)$ & $.40(.24)$ \\
Familiarity & $.45(.14)$ & $.56(.24)$ \\
$\quad$ Nondysphoric & $.50(.13)$ & $.55(.24)$ \\
Dysphoric &
\end{tabular}

Note. $n=18$.

curred in Phase 1, strike NEW. Also strike NEW if it is a new item. Strike OLD only if the item seems familiar but you do not remem. ber it occurring in Phase 1 on the computer. Please note that you will always strike OLD to items from the audio tape. However, you should not try to remember the tape; that's too hard. Just trust that if an item seems familiar but you do not remember it from Phase 1 , it was probably on the tape.

Before the subjects began the practice trials, the experimenter asked them to paraphase the instructions; they discussed the instructions until the experimenter was satisfied that they understood.

\section{Results}

\section{Estimates of Recollection and Familiarity}

First, the proportions of rated words judged old under inclusion and exclusion instructions were converted to estimates of recollection and familiarity (Jacoby, 1991). These estimates were separately submitted to analyses of variance, with between-subjects factors for mood (nondysphoric vs. dysphoric) and the type of test (single-item vs. paired). (The significance level was set at .05 for these and subsequent analyses.) Means and standard deviations are displayed in Table 2.

Estimates of recollection showed two reliable main effects. First, dysphoric subjects recollected fewer rated words $(.30$ vs. .43 for nondysphoric subjects), $F(1,68)=5.73, M S_{\mathrm{e}}=.05$. Second, recollection was lower on the single-item test than on the paired test $(.25$ vs. .47$), F(1,68)=18.26$. The interaction was not reliable $(F<1.00)$.

Estimates of familiarity showed no reliable differences. The paired test, however, tended to produce greater familiarity (.56 vs. .48 in the single test), $F(1,68)=2.83, M S_{\mathrm{e}}=.04, p<.10$. Other effects did not approach statistical significance $(F \mathrm{~s}<$ 1.00 ).

The results of these analyses provide evidence for a functional dissociation between recollection and familiarity that was established by subjects' emotional state; dysphoric subjects showed impaired recollection but similar levels of familiaritybased recognition. We gained further evidence of the independence of the two components by evaluating correlations between the estimates within each group of subjects and finding nonreliable associations $(p>.10)$ : in the nondysphoric group, $r(34)=.23$, and in the dysphoric group, $r(34)=-.12$.

The assumption of independent components also relies on evidence that the same criteria for responding old were used under both inclusion and exclusion instructions. We next re- 
Table 3

Mean Percentages of Words Judged Old (and Standard Deviations)

\begin{tabular}{|c|c|c|c|c|}
\hline \multirow[b]{2}{*}{ Phase and group } & \multicolumn{2}{|c|}{ Single item } & \multicolumn{2}{|c|}{ Paired } \\
\hline & Inclusion & Exclusion & Inclusion & Exclusion \\
\hline \multicolumn{5}{|l|}{ Phase 1} \\
\hline Nondysphoric & $62(13)$ & $32(13)$ & $79(16)$ & $24(13)$ \\
\hline Dysphoric & $61(13)$ & $41(18)$ & $74(18)$ & $34(21)$ \\
\hline \multicolumn{5}{|l|}{ Phase 2} \\
\hline Nondysphoric & $65(16)$ & $58(17)$ & $50(16)$ & $49(15)$ \\
\hline Dysphoric & $67(10)$ & $58(13)$ & $50(15)$ & $52(14)$ \\
\hline \multicolumn{5}{|l|}{ New distractors } \\
\hline Nondysphoric & $23(14)$ & $22(12)$ & $19(11)$ & $19(14)$ \\
\hline Dysphoric & $27(13)$ & $24(14)$ & $20(12)$ & $20(13)$ \\
\hline
\end{tabular}

Note. $n=18$.

port results from an analysis of the percentage of new items judged old, which was used to evaluate such evidence.

\section{Percentage Judged Old}

Table 3 lists means and standard deviations of the percentages of Phase 2 and new words judged old. (It also presents the same information for Phase 1 words, so that the nature of the estimates reported earlier can be better evaluated.) All percentages were based on a total of 27 items, with items for which no response was obtained omitted (less than $1 \%$ of trials, on average). The percentages were separately submitted to analyses of variance for Phase 2 and new words. Each design included betweensubjects factors for mood and type of test and a within-subjects factor for instructions (inclusion vs. exclusion). Reliable main effects are not routinely reported when they are qualified by reliable interactions.

New items. Again, the assumption about the independence of recollection and familiarity rests on evidence for the use of similar criteria in responding under inclusion and exclusion instructions. The most straightforward index of such criteria is supplied by responses to new items. The percentage of new words judged old did not vary reliably according to any of the three factors in the design. However, the results showed a trend in which subjects who took the paired test made fewer of these errors; the mean percentages of distractors judged old were $19.3 \%$ on the paired test and $23.8 \%$ on the single-item test, $F(1$, $68)=3.21, M S_{\mathrm{e}}=230.20 . p<.10$. No such trends were found for instructions to include versus exclude or for any other effects in the design (all $F \mathrm{~s}<1.00$ ). In short, these results do not challenge the independence assumption, nor do they call into question comparisons between the two mood groups. They do, however, suggest that all subjects may have used different criteria for judging test items as a function of the presence or absence of paired words. Therefore, comparisons of recollection and familiarity across the type of test must be viewed with caution.

Phase 2 items. The percentage of heard words judged old differed reliably according to the type of test, $F(1,68)=15.42$, $M S_{\mathrm{e}}=313.79$. Subjects in the single-item condition endorsed $61.7 \%$ of heard words on average, compared with $50.1 \%$ for subjects in the paired condition. This difference is not surprising, if one considers that the partners on the paired test were new to subjects' experience; their presence on the test ought to have reduced the overall feeling of familiarity established by the display or may even have provided misleading routes for recollection.

Although the level of endorsement of heard items appears to be at chance on the paired test, subjects clearly endorsed many more heard than new items, which suggests that some degree of discrimination occurred.

Of greater importance is the reliable interaction of type of test with instructions, $F(1,68)=5.26, M S_{\mathrm{e}}=114.04$. On the paired test, subjects endorsed the same percentage of heard words under each instruction $(50.1 \%)$, but the subjects who took the single-item test endorsed more words under instructions to include $(65.7 \%$ vs. $57.7 \%$ under exclusion). This interaction is addressed in the Discussion. Apart from the main effect of instructions, no other effects approached statistical significance $(F \mathrm{~s}<1.00)$.

\section{Performance Across Blocks}

A final set of analyses was performed on all measures of recognition by including a factor for blocks of items. There were three blocks of trials under both inclusion and exclusion instructions, with 9 items included in each. Instructions alternated, but the order was counterbalanced within experimental and mood groups. We report only the reliable effects that involved the blocking factor, alone or in combination with other factors in each design. Although our predictions did not concern such a factor, a reasonable question to ask is whether performance by dysphoric subjects deteriorated across blocks to a greater degree than what was the case for nondysphoric subjects.

Estimates of recollection and familiarity. Estimates of recollection $^{2}$ decreased across the three blocks $(.44, .35$, and .30$)$ regardless of mood and test conditions, $F(2,136)=8.13, M S_{\mathrm{e}}$ $=.05$. Similarly, estimates of familiarity also decreased but only

\footnotetext{
2 The basis for the drop in recollection was a drop in the percentage of targets judged old on the inclusion test $(78 \%, 68 \%$, and $61 \%$ across blocks); percentages were fairly constant during exclusion $(34 \%, 34 \%$, and $31 \%$ ).
} 
on the single-item test. The interaction ${ }^{3}$ of blocks with type of test was reliable, $F(2,130)=4.42, M S_{\mathrm{e}}=.04$. Mean estimates were $.62, .47$, and .38 on the single-item test and $.55, .55$, and .50 on the paired test. The provision of prior context apparently maintained a rather constant sense of familiarity across blocks of trials.

Percentage of items judged old. For all subjects new words were endorsed less frequently across blocks $(24 \%, 22 \%$, and $19 \%), F(2,136)=3.74, M S_{\mathrm{e}}=230.59$. Finally, heard words were also endorsed less frequently across blocks $(65 \%, 54 \%$, and $50 \%), F(2,136)=24.21, M S_{e}=356.90$. In general, subjects became more conservative in their willingness to judge items as old as the number of test items increased.

\section{Discussion}

The primary finding in this study was a depressive impairment in the recollective component of recognition memory, in the absence of differences in estimates of familiarity. This finding is consistent with theories that predict impairments in controlled processing (e.g., Ellis \& Ashbrook, 1988; Hertel \& Hardin, 1990; Williams et al., 1988). Without the process dissociation procedure, however, the results from the (typical) inclusion condition in Phase 1 and from Phase 2 recognition showed comparable performance across mood.

Depressed mood is yet another factor that establishes a dissociation between two components of performance on tests of memory. One component is generally taken to reflect the automatic effects of past experience. Jacoby (1991, p. 532) defined automatic influences of memory as those influences that remain constant, regardless of one's intention to remember. They affect recognition judgments even when one is trying to oppose or counteract the effects of the past, as is the case under exclusion instructions. The conscious recollective component is defined purely in terms of the difference in performance that results from intent to use versus not use past experience in performing a current task. Such definitions avoid the problems that arise in trying to define controlled versus automatic processes purely in terms of single testing conditions or response characteristics. $^{4}$

Like Jacoby, we prefer to think of performance on memory tests in componential terms rather than to assume that different types of tests tap different unitary processes. In the latter regard, however, a number of investigators have shown that depressed moods are associated with differences on explicit memory tests but not on those of implicit memory (Denny \& Hunt, 1992; Hertel \& Hardin, 1990; Watkins, Mathews, Williamson, \& Fuller, 1992). Tests of explicit memory-like free and cued recall-are more likely in a relative sense to invite recollective or controlled procedures, whereas implicit-memory tests-like stem and fragment completion-are more likely to invite automatic influences of prior experience with the materials. Each type of test, however, can be shown to vary in the extent to which that tendency holds (see Jacoby et al., 1993).

Why were depressive deficits found in recollection but not in feelings of familiarity? In comparison with recollective components of retrieval, a sense of familiarity is less likely to be affected by the degree of controlled processing during initial exposure in Phase 1 (see Jacoby et al., 1993). If depression lim- ited the degree of cognitive control during a study phase, then the effects would be seen in controlled procedures at test. This reasoning follows the general scheme known as transfer-appropriate processing (Morris, Bransford, \& Franks, 1977). Alternatively, if depression were not associated with differences in Phase 1 processing, deficits in recollection would simply reflect the lack of controlled reference to the past at the time of the test and the possibly heavier reliance on feelings of familiarity.

We did not examine possible differences in the use of controlled procedures during Phase 1 . Instead, we manipulated the conditions under which recognition judgments were made in an attempt to improve cognitive control on the test. The representation of the partners from the initial rating task exerted several effects. First, the paired test clearly increased recollection, but it also tended to elevate familiarity. These effects on the parameter estimates, however, must be understood cautiously in the context of other effects of the type of test. The subjects tended to endorse fewer new items on the paired test than on the single-item test (although not reliably so); they were also more conservative in endorsing previously heard words. Both of these differences could well reflect the presence of the new partners with the heard and new items presented for recognition. An unfamiliar context would of course not aid recollection of the heard words and further would make all such items-heard and new-seem less familiar, but old partners would elevate recollection, familiarity, or both.

In the absence of old partners, list discrimination was more difficult. Recollection of Phase 1 targets can be seen as a problem in list discrimination that arose primarily on the exclusion test. Furthermore, this interpretation is relevant to the effect of instructions on single-item recognition of heard words from Phase 2. On the single-item test, lower rates of endorsing Phase 2 words under exclusion may have reflected false recollection (Phase 2 words that were excluded on the basis of believing that they had occurred in Phase 1). This problem in list discrimination is central to performance on exclusion trials. That is, when

\footnotetext{
${ }^{3}$ The data from 3 subjects in the paired test were missing from this analysis. They recollected all words in at least one of the blocks, and so the estimate of familiarity was indeterminate.

${ }^{4}$ As discussed by Jacoby, Toth, and Yonelinas (1993), the process dissociation procedure is both similar to and different from procedures that rely on signal detection theory. Like the process dissociation procedure, signal detection theory is based on an independence assumption: Discriminability and bias are independent contributors to performance on recognition tests. Signal detection theory, however, is a single-process theory with respect to memory components, whereas the process dissociation procedure includes two memory components. The familiarity component of the process dissociation procedure, moreover, can be understood to include the subcomponents of guessing influenced by prior exposure in the experiment and guessing influenced by uncontrolled bias. The component for familiarity can therefore be analyzed with signal detection methods to correct estimates on the basis of uncontrolled guessing; $d^{\prime}$ can measure the memory subcomponent of familiarity. An alternative method is to subtract base rates (proportion of new items endorsed) from familiarity estimates. For our results this method produced average estimates of familiarity (corrected for guessing) of . 24 on the single-item test and .36 on the paired test but no differences associated with mood. (For a more thorough treatment of these issues, see Jacoby et al., 1993.)
} 
the same problem characterizes judgments about Phase 1 words, such words are not excluded. In this sense one may say that something is familiar when one has encountered it before but does not know where. In keeping with this line of reasoning, list discrimination for Phase 2 items is arguably less of a problem on the paired test; the new partners provide information to rule out Phase 1 membership.

Regardless of whether our interpretations of effects from the test and instruction manipulations are correct, we emphasize that none of these effects depended on mood. Any notion that dysphoric subjects were given particular advantage by aids for list discrimination or by increased familiarity was unsupported. Therefore, the degree of controlled processing during Phase 1 may have been responsible for the depressive deficit in recollection. It is important to keep in mind, however, that distinguishing between encoding versus retrieval explanations is ultimately impossible (see Watkins, 1990). Cognitive control on the test may have been affected in ways unrelated to our manipulation of context.

In very general terms, depressive deficits in controlled procedures are consistent with neuropsychological evidence in regard to attention and depression. Recent research has identified regions of the frontal lobes as loci of cognitive procedures involved in voluntary attention, monitoring, and other metacognitive activities (see the review by Mayes, 1988). Moscovitch and Winocur (1992), for example, provided evidence that dividing the attention of neurologically unimpaired subjects mimics effects of frontal-lobe damage. Another example is Posner's (1992) use of positron emission tomography techniques to observe increased activation in certain frontal regions during prolonged maintenance of attention. Such scans have also revealed that hypometabolism in the frontal lobes correlates with degree of depression, as do strokes that primarily affect the left frontal region (Resnick, 1992). Thus, there are possible neurophysiological bases for inferring that depressed moods are associated with reduced cognitive control.

\section{References}

Beck, A., Ward, C., Mendelson, M., Mock, J., \& Erbaugh, J. (1961). An inventory for measuring depression. Archives of General Psychiatry, 4, 561-571.

Channon, S., Baker, J. E., \& Robertson, M. M. (1993). Effects of structure and clustering on recall and recognition memory in clinical depression. Journal of Abnormal Psychology, 102, 323-326.

Deardorff, W. W., \& Funabiki, D. (1985). A diagnostic caution in screening for depressed college students. Cognitive Therapy and Research, 9, 277-284.

Denny, E. B., \& Hunt, R. R. (1992). Affective valence and memory in depression: Dysfunction of recall and fragment completion. Journal of Abnormal Psychology, 101, 575-580.

Ellis, H. C., \& Ashbrook, P. W. (1988). Resource allocation model of the effects of depressed mood states on memory. In $\mathrm{K}$. Fiedler \& J. Forgas (Ed.), Affect, cognition, and social behavior (pp. 25-43). Toronto: Hogrefe.

Hartlage, S., Alloy, L. B., Vazquez, C., \& Dykman, B. (1993). Automatic and effortful processing in depression. Psychological Bulletin, 113, 247-278.
Hasher, L., \& Zacks, R. T. (1979). Automatic and effortful processes in memory. Journal of Experimental Psychology: General, 108, 356388.

Hertel, P. T., \& Hardin, T. S. (1990). Remembering with and without awareness in a depressed mood: Evidence of deficits in initiative. Journal of Experimental Psychology: General, 119, 45-59.

Hertel, P. T., \& Rude, S. S. (1991). Depressive deficits in memory: Focusing attention improves subsequent recall. Journal of Experimental Psychology: General, 120, 301-309.

Jacoby, L. L. (1991). A process dissociation framework: Separating automatic from intentional uses of memory. Journal of Memory and Language, 30, 513-541.

Jacoby, L. L., \& Dallas, M. (1981). On the relationship between autobiographical memory and perceptual learning. Journal of Experimental Psychology: General, 3, 306-340.

Jacoby, L. L., Toth, J. P., \& Yonelinas, A. P. (1993). Separating conscious and unconscious influences of memory: Measuring recollection. Journal of Experimental Psychology: General, 122, 139-154.

Kuçera, H., \& Francis, W. N. (1967). Computational analysis of present-day American English. Providence, RI: Brown University Press.

Mandler, G. (1980). Recognizing: The judgment of previous occurrence. Psychological Review, 87, 252-271.

Mayes, A. R. (1988). Human organic memory disorders. New York: Cambridge University Press.

Morris, C. D., Bransford, J. D., \& Franks, J. J. (1977). Levels of processing versus transfer appropriate processing. Journal of Verbal Learning and Verbal Behavior, 16, 519-533.

Moscovitch, M., \& Winocur, G. (1992). The neuropsychology of memory and aging. In F. I. M. Craik \& T. A. Salthouse (Ed.), The handbook of aging and cognition (pp. 315-372). Hillsdale, NJ: Erlbaum.

Posner, M. I. (1992). Attention as a cognitive and neural system. Current Directions in Psychological Science, 1, 11-14.

Resnick, S. M. (1992). Positron emission tomography in psychiatric illness. Current Directions in Psychological Science, 1, 92-98.

Roediger, H. L., III, \& McDermott, K. B. (1992). Depression and implicit memory: A commentary. Journal of Abnormal Psychology, 101, 587-591.

Spielberger, C. D., Gorsuch, R. C., Lushene, R., Vagg, P. R., \& Jacobs, G. A. (1983). Manual for the State-Trait Anxiety Inventory. Palo Alto, CA: Consulting Psychologists Press.

Toth, J. P., Reingold, E. M., \& Jacoby, L. L. (1994). Toward a redefinition of implicit memory: Process dissociations following elaborative processing and self-generation. Journal of Experimental Psychology: Learning, Memory, and Cognition, 20, 290-303.

Watkins, M. J. (1990). Mediationism and the obfuscation of memory. American Psychologist, 45, 328-335.

Watkins, P. C., Mathews, A., Williamson, D. A., \& Fuller, R. D. (1992). Mood-congruent memory in depression: Emotional priming or elaboration? Journal of Abnormal Psychology, 101, 581-586.

Watts, F. N., Morris, L., \& MacLeod, A. K. (1987). Recognition memory in depression. Journal of Abnormal Psychology, 96, 273-275.

Williams, J. M. G., Watts, F. N., MacLeod, C., \& Mathews, A. (1988). Cognitive psychology and emotional disorders. New York: Wiley.

Yonelinas, A. P., \& Jacoby, L. L. (in press). Differential effects of list length on familiarity and recollection: Process dissociations in recognition memory. Canadian Journal of Psychology.

Received June 8, 1993

Revision received April 29, 1994

Accepted May 9, 1994 